\title{
Development of Information Support for Intelligent CAD of Cutting Processes
}

\author{
K.A. Altunin, M.V. Sokolov* \\ Department of Computer-Integrated Systems in Mechanical Engineering, Tambov State Technical University, \\ 116, Sovetskaya St., Tambov, 392032, Russia \\ *Corresponding author. Tel.: + 7 (4752) 6306 18.E-mail: tmmsii@tmmsii.jesby.tstu.ru
}

\begin{abstract}
The effectiveness of machine-building production depends on the extent to which the quality and accuracy requirements of products are met. The availability of computer-aided design (CAD) system, which offers the user to choose from the list of possible parameters of the cutting process the optimal ones under given conditions, would significantly improve the efficiency of the operating procedure. This problem can be solved by the use of CAD systems in the development of the operating procedure of parts machining. The use of various methods of artificial intelligence for the development of cutting processes CAD will facilitate the solution of difficult-to-formalize tasks arising in the design process. To create information support for intelligent $\mathrm{CAD}$ of cutting processes, it is necessary to design a database and a knowledge base of the main parameters of the processes being studied. First, the development of a database of the main parameters of the cutting processes is described. It consists of the following parts: a database of cutting tools, a database of metal-cutting machines and a database of materials to be processed. Structural schemes are developed and tables for each of the elements are compiled. The steps for creating a knowledge base for intelligent CAD systems of cutting processes are considered. A model of representation of knowledge and the knowledge base of cutting processes based on it are created. The structure of the frame model of the knowledge base for external lathe machining of stepped shafts is described. The knowledge base presents the frame structures: "Machines", "Processing conditions", "Cutting tools", "Cutting modes", "Parts", "Materials", "Workpieces", "Fixtures". More than 90 rules have been developed, according to which the values of frame slots are chosen. Thus, the problem of creating information support for intellectual CAD of cutting processes through the development of a database and a knowledge base of the main processes of materials machining has been solved.
\end{abstract}

\section{Keywords}

Database; knowledge base; cutting process parameters; frames.

(C) K.A. Altunin, M.V. Sokolov, 2017

\section{Introduction}

At present, the reduction of design period and selection of optimal parameters of the cutting process are the most important requirements for the development of the operating procedure. The availability of CAD, which offers the user to choose from the list of possible parameters of the cutting process the optimal ones under given conditions, would significantly improve the efficiency of the operating procedure.

The application of various methods of artificial intelligence for the development of CAD of the processes of the mechanical processing of materials will improve the system's performance, increase the speed of processing input data and facilitate the solution of difficult-to-formalize problems that arise during the design process.

Methods for modeling and optimizing the mechanical processing of materials were considered in the works of S.S. Silin, E. Ullmann, E. Vieman, V.A. Kudinov, M.L. Orlikov, G. I. Granovsky, V.G. Granovsky [1-5], and others. However, little research has been done in the field of modeling and optimization of the cutting process, taking into account its dynamic component.

The problems of CAD development are considered, in particular, in the works of G.B. Eugenev, I. P. Norenkov, A. A. Cherepashkov, 
N.V. Nosov, K. Lee, M. Groover, E. Zimmers, A.W. Vinit [6-11] and others. But little research has been done in the field of creating intelligent CAD and its application to modeling and optimization of cutting processes.

The amount of information that needs to be analyzed by a technologist when designing a partprocessing process is quite significant. It includes data on the material being processed (type, hardness, etc.), the cutting tool (its kind, type, material), cutting modes (cutting speed, advance, cutting depth, cutting force), metalworking equipment (technical data on the machine). The systematization of these data will facilitate their further processing. Hence, there is a need to create a database (DB) of the main parameters of the cutting process.

The problem of choosing certain parameters of the cutting process (such as a choice the material of the cutting part of the tool and determining its optimal geometry, the processing parameters, etc.) is difficult to formalize. By a difficult-to-formalize problem we mean a problem that does not have a clear decision algorithm. In this case, the knowledge of an expert in the area is required to make the right choice. To help solve such a difficult-to-formalize problem, it is necessary to create a model for providing knowledge for the subject area under study. This model of knowledge representation is the basis for the knowledge base (KB) of the processes of materials machining.

The purpose of this work is to develop information support for intelligent CAD systems of the mechanical processing of materials. To do this, DB and $\mathrm{KB}$ on the processes under study should be designed.

\section{DB Structure of the Main Processes of Materials Machining}

DB of the main processes of materials machining consists of the following components:

1. Cutting tools DB. It contains information about the geometric parameters of the cutting tool. Such a database can be made for cutting tools of the main processes of blade material processing (turning, drilling, core drilling, reaming, milling). In order to increase the efficiency of DB being developed, one should concentrate on the data on the most common tools. In this case, standard universal cutting tools should be included in the table, since there are separate design programs for special tools. Thus, to create cutting tools DB, one can use GOST materials.
2. Workpiece materials DB. The tables should include data on the physico-mechanical and thermophysical properties of the materials being processed. Only those properties of the materials that do not change in the course of heat treatment and do not depend on the type and condition of the workpiece (such as density, heat resistance, etc.) are recorded in the database.

3. Metalworking equipment DB. To create this database, you can use the classification of machines by the type of processing and their technical data.

\subsection{Cutting Tools DB}

Let us consider the development of cutting tools DB illustrating turning tools as an example. The proposed database is built on the basis of the existing GOSTs for cutting tools. As an example, let us consider the structure of the database of high-speed and hard-alloy turning tools which are most frequently used in turning. These types of tools are provided with appropriate GOSTs. These normative documents contain data on the design dimensions of the tool, which can be used to build the database. Tool marks, for example 2101-0001, can be used as a primary key, which will serve to uniquely identify table entries. Also in GOSTs you can find tables that relate the cross-section of the tool with the radius at the top [12].

Physico-mechanical and thermo-physical properties of the material of the cutting part of the tool are summarized in a separate table. In the DB, data on the design and dimensions of the replaceable insert is also entered in the form of separate tables. To identify the insert in the $\mathrm{DB}$, the primary key is the insert number.

Data on the geometry of the tool, in particular, on the angles (main $\varphi$, auxiliary $\varphi 1$, and angle at the vertex $\varepsilon$ ) are also summarized in a separate table.

Scheme of the turning tools DB (exemplified by high-speed cutters) is shown in Fig. 1. The created logical scheme of DB allows systematizing data on geometric and constructive parameters of the cutting tool.

\subsection{Workpiece Materials DB}

The list of materials processed on metal cutting machines is quite extensive. Nevertheless, we can distinguish three main groups: steel, cast iron and nonferrous metals and alloys. For each of these groups, separate tables were compiled containing data on the physico-mechanical and thermo-physical properties of these materials. The properties of materials that do not change as a result of heat treatment and do not depend 


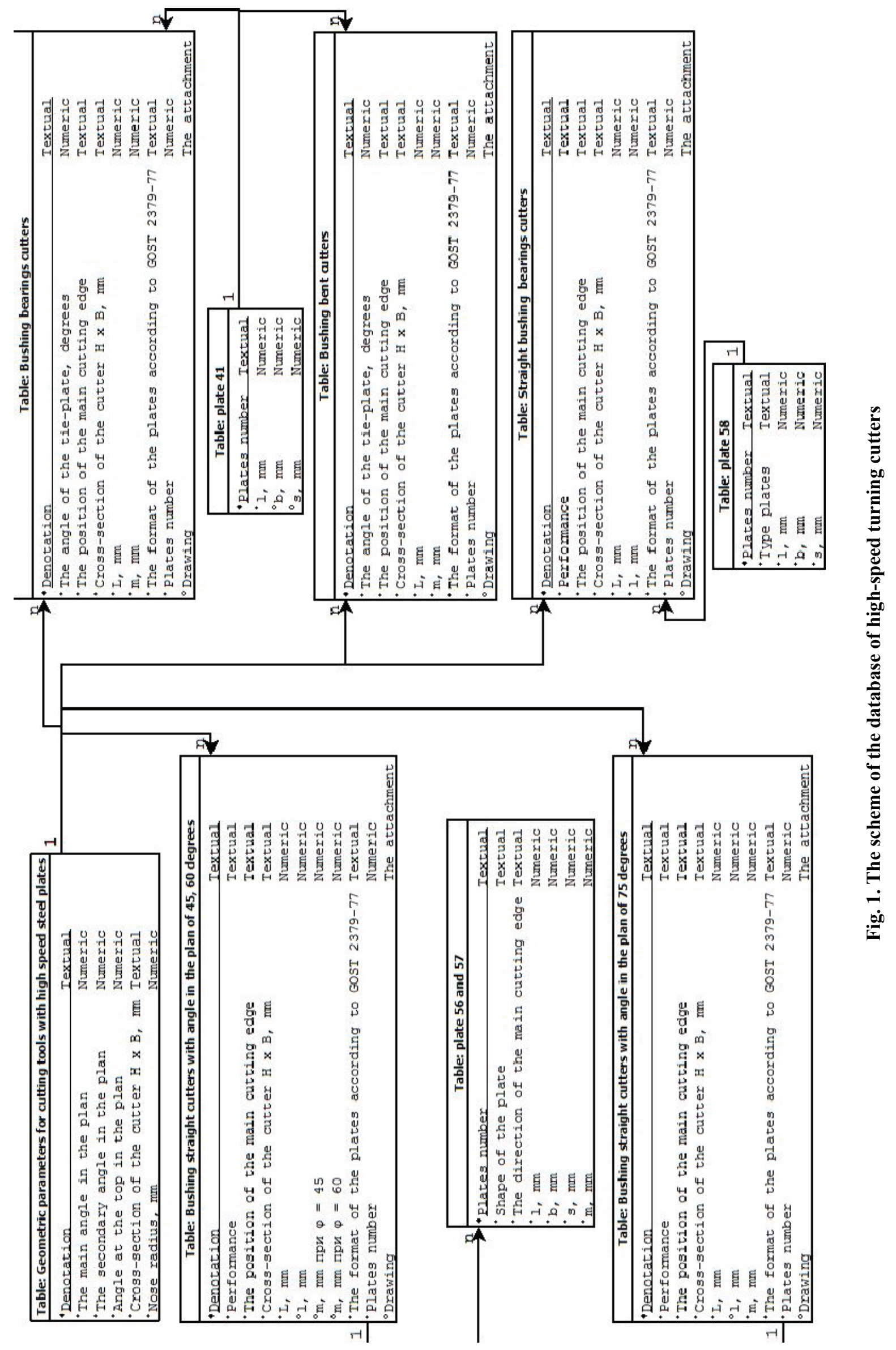


on the type and condition of the workpiece (density, heat resistance, etc.) were entered in the database. As a primary key, the material grade was selected.

Also, in the table with the properties of nonferrous metals and alloys, a column "Type of metal or alloy" was added. It includes such categories as: "Copper alloy", "Aluminum alloy", "Aluminum", "Copper". This classification facilitates the calculation of the parameters of the cutting process for non-ferrous metals and alloys.

\subsection{Metalworking equipment $D B$}

For metalworking equipment DB let us consider the classification of machine tools based on the kind of processing. According to it, metal-cutting machines are divided into nine groups, which, in turn, are subdivided into nine types. This classification can be used to create a database of metal cutting machines [13].

The scheme of metal-cutting machines DB is shown in Fig. 2.

The classification of machines according to the type of processing and their technical data is used as a basis of the DB scheme. According to the scheme, first, a master table is created containing data on the group and type of machines. In the auxiliary table associated with it, data on the parameters of the machines of a particular model is entered (as shown in the example of screw-cutting and vertical-drilling machines). The interrelation between tables is performed through the field "Code". This field contains a number, the first digit of which defines the machine group, and the second digit - its type.

Let us consider the compiling of the auxiliary table illustrating screw-cutting lathes as an example. Basic information about the parameters of the tools of this technological type can be found in their technical data. The parameters which can be needed for modeling and optimizing turning are: engine power, machine efficiency, minimum spindle speed, maximum spindle speed, minimum longitudinal feed, maximum longitudinal feed, minimum cross feed, maximum cross feed, maximum diameter of the workpiece over the bed, maximum diameter of the workpiece over the slide, the height of the cutter set in the tool holder, maximum length of the workpiece being processed. All these data are the basis for compiling a table. It is proposed to use the model of the machine as a primary key in the table. Hence we get a table containing the main parameters of screwcutting machines.

Thus, by compiling tables with basic parameters of metal-cutting machines, corresponding to their basic types, it is possible to create the database of metalcutting lathes.

\section{Development of Materials Machining Processes KB}

The KB contains facts and rules, according to which, depending on the input data, a decision is made. Facts are short-term data that can change in the process of solving a problem. The rules present more long-term data on how to generate new facts and hypotheses from the available data.

The rules are widely used as a basis for the KB. Having analyzed reference literature on the design of operation procedures, we can formulate rules for choosing various parameters of the cutting process.

However, knowledge systems based on rules can be quite extensive. This can lead to the appearance of repetitive knowledge or knowledge conflicting with each other. To prevent this, we have to carry out the monitoring of the added rules, which leads to the system complication and loss of its operability.

Due to their versatility and flexibility, frames are a perspective form of knowledge representation [14]. A frame is a structure for describing a stereotyped situation, consisting of the characteristics of this situation and their values. Characteristics are called slots, and values are called slot fillers. A set of frames that simulates a particular subject area is a hierarchical structure into which frames are joined.

A frame with unfilled slots is called a protoframe. A frame with filled slots is called a frame instance.

However, the way of presenting knowledge in the form of a frame system has a significant drawback the complexity of processing exceptions.

There is another way of interpreting frames [15]. If the concept of the frame is expanded so that it covers the properties of objects, then it becomes possible to treat any object as a frame. This method can be implemented using CLIPS language and objectoriented language COOL built in it. In CLIPS language, object-oriented expert systems can be produced that allow to use rules (considered as small pieces of knowledge) and, at the same time, provide the opportunity to organize larger fragments of knowledge in the form of objects in order to simplify development and maintenance. Rules can be used to work with facts or objects, and therefore CLIPS has all the advantages of two categories of expert system tools - based on rules and based on objects.

Thus, when developing cutting processes $\mathrm{KB}$, it seems most reasonable to use the method of providing knowledge based on a combination of a frame structure and product rules. 


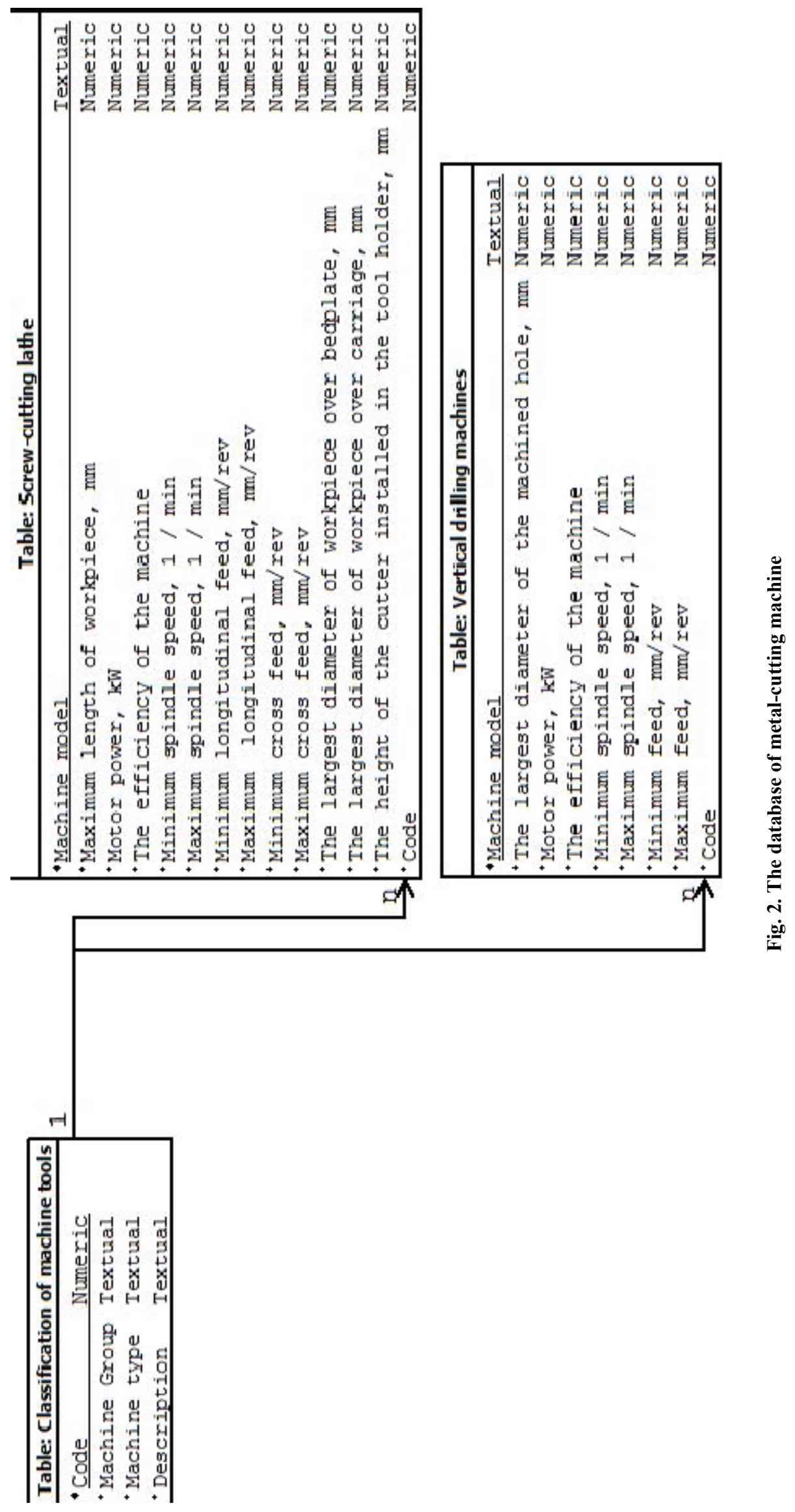




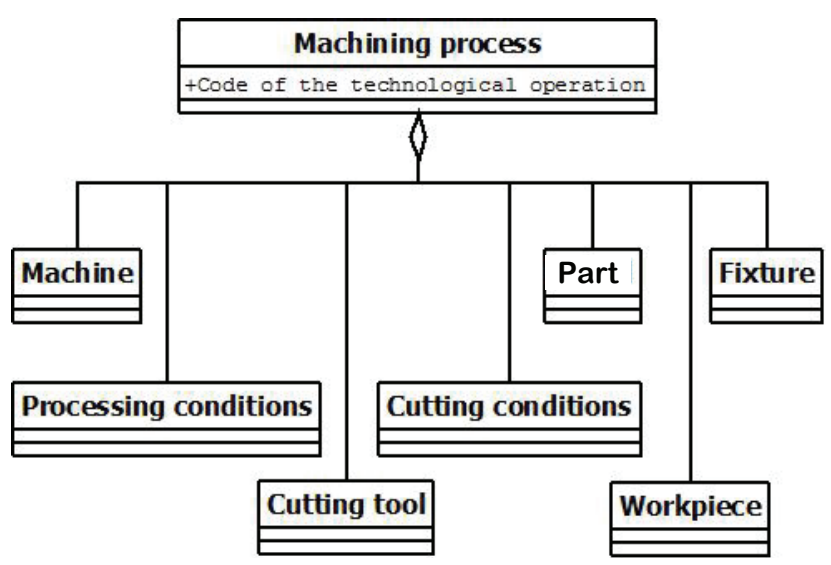

Fig. 3. Block diagram of the materials machining process $\mathrm{KB}$

$\mathrm{KB}$ for intelligent $\mathrm{CAD}$ of materials machining processes contains:

- data on process equipment (machines) used for workpiece machining;

- data on machining conditions (rigidity of the machine-fixture-tool-part system, continuity of cutting, etc.);

- data on the cutting tool (its kind, type, material);

- mode parameters, such as cutting speed, feed, cutting depth, cutting force;

- part parameters and requirements for its manufacture;

- data on the method of workpiece producton;

- data on how to set a workpiece in the fixture.

The frame structures "Machine", "Processing conditions", "Cutting tools", "Cutting conditions", "Part", "Material", "Workpiece", "Fixture" are presented in the DB. DB is a single system of interrelated frames that have a hierarchical structure. A frame can be presented as a class whose attributes play the role of slots. Each of these classes can be divided into subclasses. Their attributes will vary depending on the particular cutting process.

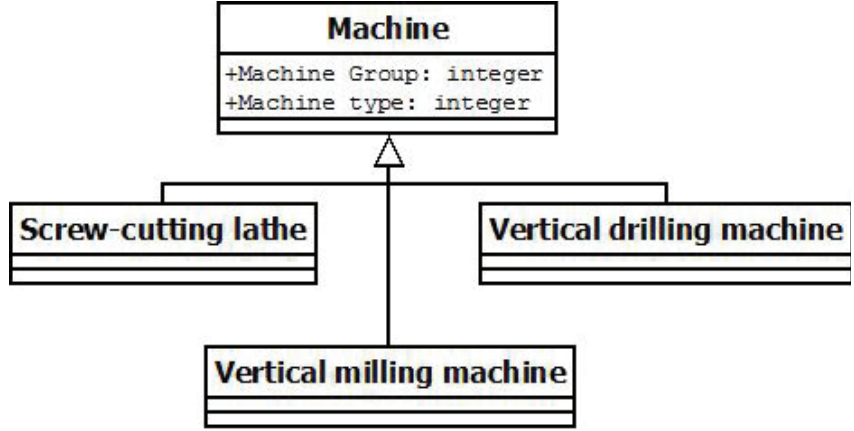

Fig. 4. The hierarchical structure of the frame "Machine"

The structure of the DB frame model of intelligent $\mathrm{CAD}$ of materials machining processes is shown in Fig. 3 in the UML notation. DB is a single system of interrelated frames, which has a hierarchical structure. A frame can be presented as a class whose attributes play the role of slots. At the top of the hierarchy is the class "Machining process", which determines the type of machining (turning, milling, drilling, etc.). According to the unified system of technological documentation, the code of the operation procedure is selected as an attribute.

The frame structures "Machine", "Processing conditions", "Cutting tool", "Cutting modes", "Part", "Workpiece", "Fixture" are presented in the DB. Each of these classes can be divided into subclasses. Their attributes will vary depending on the specific cutting process. Let us illustrate their creation by the example of turning the main metals and alloys used in industry.

The "Machine" frame and its hierarchical structure are shown in Fig. 4. The abstract frame "Machine" contains the slots "Machine group" and "Machine type". According to these slots, the machines are classified according to the type of processing. For example, Fig. 4 shows the division into frames "Screw-Cutting Lathe", "Vertical Drilling Machine" and "Vertical Milling Machine". Fig. 5 shows the slots that are

\begin{tabular}{l} 
Screw-Cutting lathe \\
\hline +Machine model: string \\
+Maximum length of workpiece, mm: integer \\
+Motor power, $\mathrm{kW}$ : integer \\
+The efficiency of the machine: integer \\
+Minimum spindle speed, $1 / \mathrm{min}$ : integer \\
+Maximum spindle speed, $1 / \mathrm{min}:$ integer \\
+Minimum longitudinal feed, mm/rev: integer \\
+Maximum longitudinal feed, mm/rev: integer \\
+Minimum cross feed, nm/rev: integer \\
+Maximum cross feed, nm/rev: integer \\
+The largest diameter of workpiece over bedplate, mm: integer \\
+The largest diameter of workiece over carriage, mm: integer \\
+The height of the cutter installed in the tool holder, mm: integer \\
\hline
\end{tabular}

Fig. 5. Basic structure of the frame "Screw-Cutting Machine" 
contained in the frame "Screw-Cutting Machine". They correspond to the basic characteristics of the machine, taken from the technical specification.

The "Cutting tool" frame and its hierarchical structure are shown in Fig. 6. The abstract frame "Cutting tool" contains the "Cutting tool kind" slot. In this slot, the kind of cutting tool is selected depending on which operation procedure is chosen. The value of the slot "Operation procedure code" is inherited from the "Machining process" frame. As a case in point, Fig. 6 shows the division into frames "Cutters", "Drills" and "Mills".

The hierarchical structure of the "Cutters" frame will be considered separately (Fig. 7). According to the type of equipment, the cutters can be divided into turning, planing, grooving, for automatic or semiautomatic machines, boring for horizontal boring machines, special for special machines. In order to take into account this classification, a slot "Kind of the cutter" was created. Also in Fig. 7 there are the slots of the frame "Turning Cutter", which reflect its geometric parameters and classification on various grounds. If you take a specific type of processing, some of the slots will acquire default values. So, for external turning of stepped shafts, the slot "Classification by processing type" will have the value "Straight-through cutter", and the slot "Cutter mandrel cross-section" "Rectangular".

Let us consider the "Part" frame (Fig. 8). It includes slots storing data on the mass of the part, the dimensions of the stage being processed, the quality

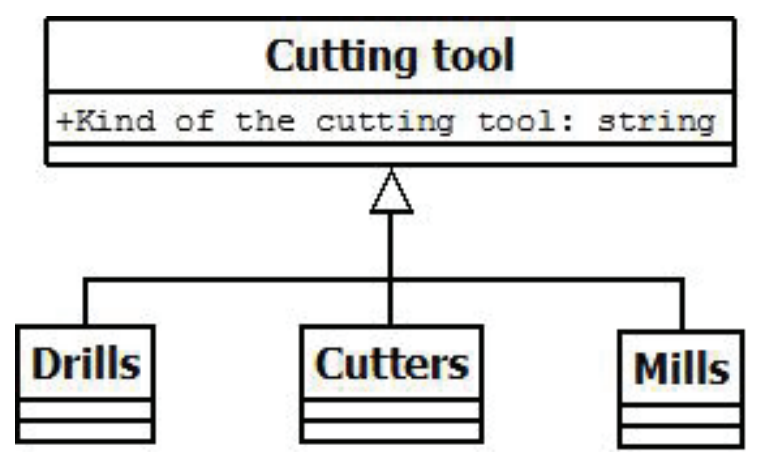

Fig. 6. Hierarchical structure of the frame "Cutting tool"

class of accuracy of the dimensions of this stage, the roughness parameters of the surfaces being processed. There must be also a slot containing the brand of the material of the part. To display the physico-mechanical and thermo-physical properties of the material of the part, a "Material" frame is created. It is part of the "Part" frame.

The "Workpiece" frame (Fig. 9) consists of slots containing data on the method of producing the workpiece (rolling, stamping, casting), the condition of the surface of the workpiece (with crust, without crust, pre-processes) and the geometric parameters of the workpiece.

The "Processing Conditions" frame (Fig. 10) contains slots with data on the rigidity of the system "machine - fixture - cutting tool - part" (increased, normal, insufficient), cutting conditions (interrupted

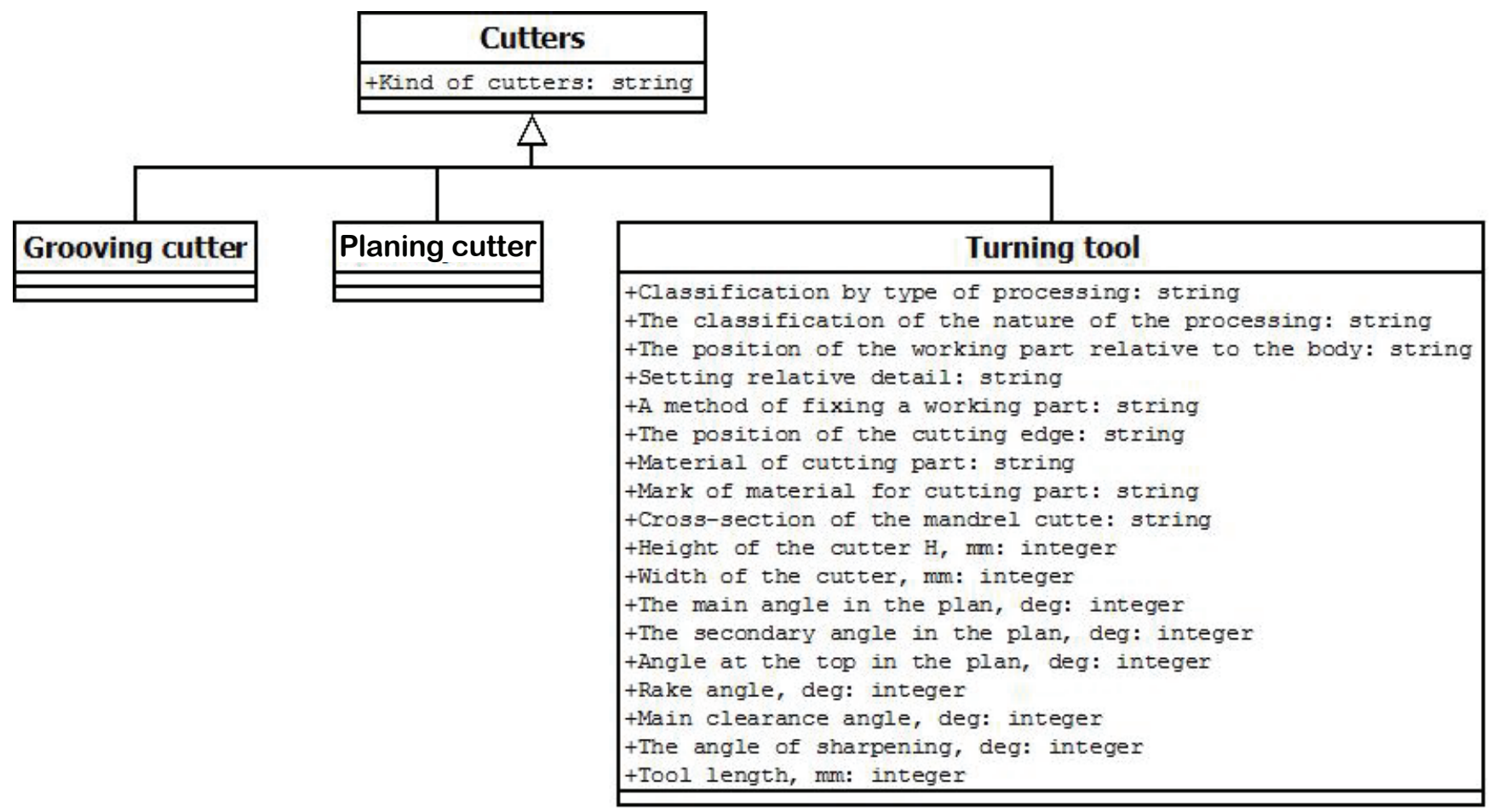

Fig. 7. Hierarchical structure of the frame "Cutters" 


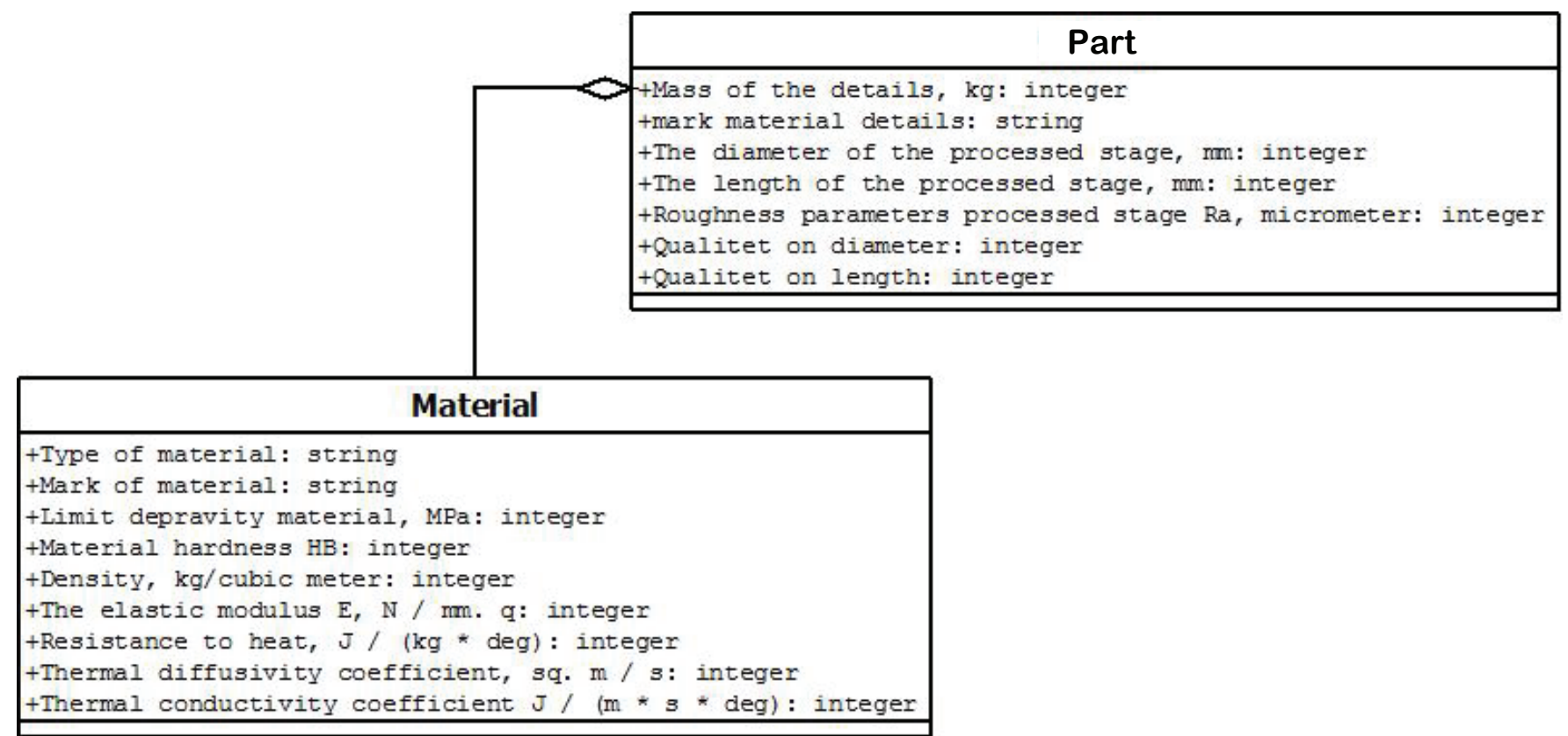

Fig. 8. Structure of the frame "Part"

\begin{tabular}{|l|}
\hline \multicolumn{1}{|c|}{ Workpiece } \\
\hline +A process for preparing: string \\
+Surface condition: string \\
+Workpiece length, mm: integer \\
+Machining diameter, nm: integer \\
+Workpiece diameter, nm: integer \\
+Length to diameter ratio: integer \\
\hline
\end{tabular}

Fig. 9. Structure of the frame "Workpiece"

cutting, continuous cutting), type of production (single, batch, mass), type of processing (roughing, semifinishing, finishing).

The "Cutting conditions" frame stores data on the mode parameters of the cutting process. Its structure is shown in Fig. 11.

The "Fixture" frame (Fig. 12) consists of slots containing data on the way the workpiece is fixed in the fixture. With regard to external turning of stepped shafts, this slot can take the following values: positioning the workpiece in the centers, positioning the workpiece in the holder, the workpiece is fixed in the holder and supported by the center.

\begin{tabular}{|l|}
\multicolumn{1}{|c|}{ Cutting conditions } \\
\hline +Cutting depth, mm: integer \\
+Feed per revolution, mm/rev: integer \\
+Cutting speed, $\mathrm{m} / \mathrm{min}$ : integer \\
+Spindle speed, $1 / \mathrm{min}$ : integer \\
+The normal component of the cutting force, $\mathrm{N}$ : integer \\
+The tangential component of cutting force, $\mathrm{N}$ : integer \\
+The number of passes: integer \\
\hline
\end{tabular}

Fig. 11. Structure of the frame "Cutting Modes"

\section{Processing conditions}

type of production: string

Fig. 10. Structure of the frame "Processing conditions"

The structure of the frame model of the KB for external turning of stepped shafts is shown in Fig. 13 in the UML notation. At the top of the hierarchy is the class "Machining process", which determines the type of machining (turning, milling, drilling, etc.). The code of the technological operation is chosen as an attribute, according to the unified system of technological documentation (4110 - turning). Since in this example a specific cutting process is considered, the frames "Machine" and "Cutting tool" are replaced by their subclasses "Screw-Cutting Machine" and "Turning tool". Frames-instances are supplemented with slots, which they inherit from the frames that are higher in the hierarchy. The default values for these slots are basic for these frames.

The choice of slot values is carried out in accordance with the rules compiled from the literature [17-18]. At present, the knowledge base contains more than 90 rules, with the help of which the optimal design parameters of the cutting process can be formed depending on specific initial data.

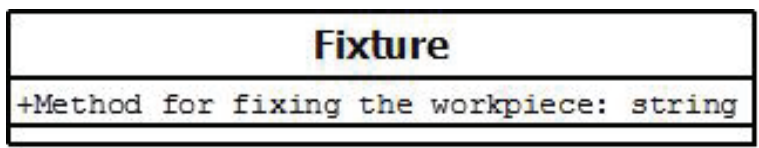

Fig. 12. Structure of the frame "Fixture" 


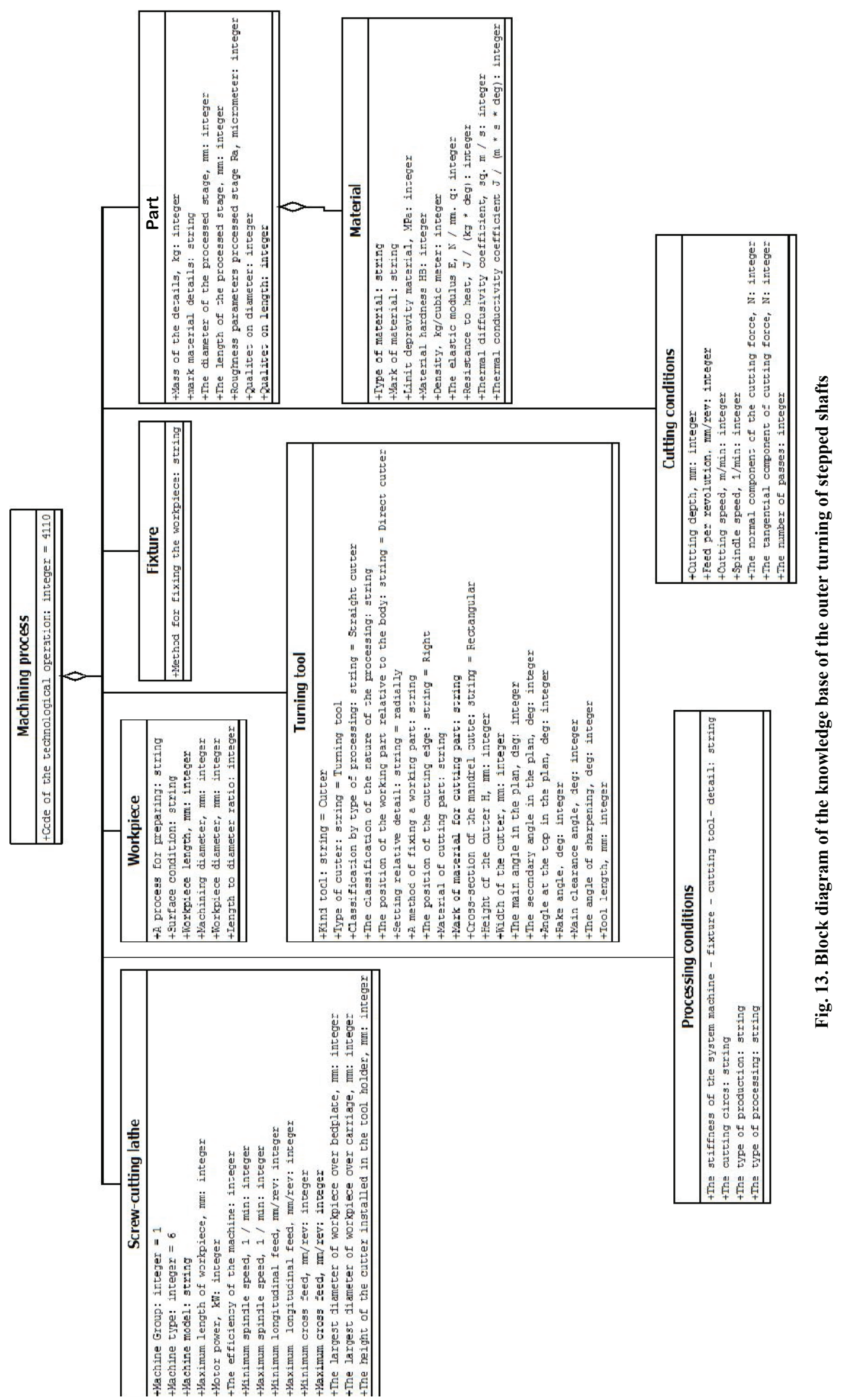


The specific type of rules will be considered by the following examples:

a) rules for determining the type of processing:

- if ("Surface roughness Ra" $>=25$ and "Surface roughness $\mathrm{Ra"}<=100$ and "accuracy quality" $<=17$ and "accuracy quality" >= 15), then "machining type" = "roughing";

- if ("Surface roughness Ra" $>=6.3$ and "Surface roughness Ra" $<=12.5$ and "accuracy quality" $<=14$ and "accuracy quality" >=12), then "machining type" = "semi-finished";

- if ("Surface roughness Ra" $>=1.6$ and "Surface roughness $\mathrm{Ra"}<=3.2$ and "accuracy quality" $<=11$ and "accuracy quality" >=7), then "machining type" = "finishing»;

$b)$ the rules for choosing the main angle in the plan:

- if ("machining type" = "finishing" and "Rigidity of the system "machine-fixture-tool-part" = "Increased rigidity" and "Length-to-diameter ratio" $<=12$ ), then "The main angle in plan, deg." = "10-20";

- if ("machining type" = "roughing" and "Rigidity of the system "machine-fixture-tool-part" = "Increased rigidity" or "Rigidity of the system "machine-fixturetool-part" = "Normal rigidity") and "Length-todiameter ratio" $<=12$ ), then "The main angle in the plan, deg." = "30-45";

- if ("machining type" = "roughing" and "Rigidity of the system "machine-fixture-tool-part"= "Insufficient rigidity" and "Length-to-diameter ratio" $<=12$ ), then "The main angle in plan, deg." = "60-75 ";

- if ("Length-to-diameter ratio" > 12), then "The main angle in the plan, deg." = "90";

c) the rules for choosing the cutter by the nature of machining:

- if ("machining type" = "roughing"), then "Classification of the cutter by the nature of machining" = "roughing";

- if ("processing type" = "finishing" or "processing type" = "semi-finished"), then "Classification of the cutter by the nature of machining" = "finishing"; tool:

d) rules for choosing the overall dimensions of the

- if ("Classification of the cutter by the nature of machining" = "roughing" and "The largest diameter of the workpiece over the bed, $\mathrm{mm} "=" 320 "$ ), then "Cutter height $\mathrm{H}, \mathrm{mm} "=$ "20" and "Cutter width B, $\mathrm{mm} "=$ "16" and "Cutter length L, mm" = "120";

- if ("Classification of the cutter by the nature of machining" = "finishing" and "The largest diameter of the workpiece being machined over the bed, mm" = "320"), then "Cutter height H, mm" = "20" and "Cutter width $\mathrm{B}, \mathrm{mm} "=$ "12" and "Cutter length L, mm" = "120";
- if ("Classification of the cutter by the nature of machining" = "roughing" and "The largest diameter of the workpiece being machined, $\mathrm{mm} "=$ "400"), then "Cutter height $\mathrm{H}, \mathrm{mm} "=$ "25" and "Cutter width B, mm" = "20" and "Cutter length L, mm" = "140";

- if ("Classification of the cutter by the nature of machining" = "finishing" and "The largest diameter of the workpiece being machined over the bed, $\mathrm{mm} "=" 400 ")$, then "Cutter height $\mathrm{H}, \mathrm{mm} "=$ "25" and "Cutter width B, mm" = "16" and "Cutter length L, $\mathrm{mm} "=$ "140 ";

- if ("Classification of the cutter by the nature of machining" = "roughing" and "The largest diameter of the workpiece being machined over the bed, $\mathrm{mm} "=$ "630"), then "Cutter height $\mathrm{H}, \mathrm{mm}$ " = "32" and "Cutter width $\mathrm{B}, \mathrm{mm} "=$ " 25 " and "Cutter length $\mathrm{L}, \mathrm{mm} "=$ "170";

- if ("Classification of the cutter by the nature of machining" = "finishing" and "The largest diameter of the workpiece being machined over the bed, $\mathrm{mm}^{\prime}=$ "630"), then "Cutter height $\mathrm{H}, \mathrm{mm}$ " = "32" and "Cutter width $\mathrm{B}, \mathrm{mm} "=$ "20" and "Cutter length $\mathrm{L}, \mathrm{mm} "=$ "170 ";

- if ("Classification of the cutter by the nature of machining" = "roughing" and "The largest diameter of the workpiece being machined over the bed, $\mathrm{mm}^{\prime}=$ "800"), then "Cutter height $\mathrm{H}, \mathrm{mm} "=$ "40" and "Cutter width $\mathrm{B}, \mathrm{mm} "=$ "32 "and" Cutter length $\mathrm{L}, \mathrm{mm} "=$ "200";

- if ("Classification of the cutter by the nature of machining" = "finishing" and "The largest diameter of the workpiece being machined over the bed, $\mathrm{mm}^{\prime}=$ "800"), then "Cutter height $\mathrm{H}, \mathrm{mm}$ " = "40" and "Cutter width $\mathrm{B}, \mathrm{mm} "=$ " 25 " and "Cutter length $\mathrm{L}, \mathrm{mm} "=$ "200 ";

e) rules for choosing the way of fixing the workpiece:

- if ("Length-to-diameter ratio" $<=4$ ), then "The way of workpiece fixing" = "workpiece positioning in the holder";

- if ("Length-to-diameter ratio" > 4 and "machining type" = "roughing"), then "The way of workpiece fixing" = "the workpiece is fixed in the holder and supported by the center";

- if ("Length-to-diameter ratio" > 4 and ("machining type" = "finishing" or "machining type" = "semifinished")), then "The way of workpiece fixing" = "workpiece positoning in the centers";

Thus, KB of the basic parameters of materials machining processes has been created, which allows processing of the initial data for modeling and optimizing the processes of materials machining. 


\section{Conclusion}

In this paper, the following results have been obtained:

1. A structural diagram of $\mathrm{DB}$ of the main parameters of materials machining processes has been designed.

2. The model of representation of knowledge and $\mathrm{KB}$ of the processes of materials machining, based on this model, have been created.

Thus, the problem of creating infomation support for intellectual CAD of machining processes through the development of a database and a knowledge base of the main processes of materials machining has been solved.

\section{Acknowledgments}

The work was carried out within the framework of the project "Development of an Intelligent System for CAD of Materials Machining Processes" under the program "Participant of the Youth Scientific and Innovation Contest" ("UMNIK").

\section{References}

1. Silin S.S. Metod podobiya pri rezanii materialov [Similarity method for materials cutting]. M.: Machine building, 1979.152 p. (Rus)

2. Ulman E. Na puti $k$ novyim rezhuschim materialam. Stanki, sovremennyie tehnologii $i$ instrument dlya metalloobrabotki [On the way to new cutting materials. Machines, modern technologies and tools for metalworking]. URL: http://www. stankoinform.ru/article/newcuttools.htm (Rus)

3. Kudinov V.A. Dinamika stankov [Dynamics of machine tools]. M.: Machine building, 1967. 359 p. (Rus)

4. Orlikov M.L. Dinamika stankov [Dynamics of machine tools]. Kiev: Vyisshay shkola, 1989. 272 p. (Rus)

5. Granovskiy G.I., Granovskiy V.G. Rezanie metallov [Metals Cutting]. M.: Vyisshaya shkola, 1985. 304 p. (Rus)

6. Evgenev G.B. Intellektualnyie sistemyi proektirovaniya [Intelligent Design Systems]. M.: N. Bauman MSTU, 2009. 334 p. (Rus)

7. Li K. Osnovyi SAPR (CAD/CAM/CAE) [Fundamentals of CAD systems]. SPb.: Piter, 2004. 560 p. (Rus)
8. Norenkov I. P. Osnovyi avtomatizirovannogo proektirovaniya [Fundamentals of Computer Aided Design]: M.: N. Bauman MSTU, 2002. 336 p. (Rus)

9. Cherepashkov A.A., Nosov N.V. Kompyuternyie tehnologii, modelirovanie $i$ avtomatizirovannyie sistemyi $v$ mashinostroenii [Computer technologies, modeling and automated systems in mechanical engineering]. Volgograd: In-Folio, 2009. 640 p. (Rus)

10.Groover M., Zimmers E. CAD/CAM: Computer-Aided Design and Manufacturing. Pearson Education, 1983. 512 p.

11.Vinit A.W. CAD-CAE Integration for Injection Molding Process. Nanyang Technological University, School of Mechanical and Production Engineering, 2005. $82 \mathrm{p}$.

12.Pestretsov S. I., Altunin K. A., Sokolov M. V. Baza dannyih rezhuschih instrumentov i obrabatyivaemyih materialov dlya SAPR protsessov rezaniya materialov [Database of cutting tools and processed materials for $\mathrm{CAD}$ of material cutting processes]. Transactions of TSTU, 2012, vol. 18, No. 3, pp. 688-695. (Rus)

13.Altunin K.A., Hramova N.A. Razrabotka bazyi dannyih metallorezhuschih stankov [Development of a database of metal-cutting machines]. In: Problemyi tehnogennoy bezopasnosti i ustoychivogo razvitiya: Sbornik nauchnyih statey molodyih uchenyih, aspirantov i studentov. Tambov: TSTU, 2015, issue VI, p. 44-49. URL: http://www.tstu.ru/book/elib/pdf/ stmu/2015/ssmu15.pdf (Rus)

14.Minskiy M. Freymyi dlya predstavleniya znaniy [Frames for knowledge representation]. M.: Energiya, 1979. $152 \mathrm{p}$.

15.Dzharratano D., Rayli G. Ekspertnyie sistemyi: printsipyi razrabotki $i$ programmirovaniya [Expert systems: principles of development and programming]. M.: OOO «ID Vilyams», 2007. 1152 p. (Rus)

16.Obschemashinostroitelnyie normativyi rezhimov rezaniya dlya tehnicheskogo normirovaniya rabot na metallorezhuschih stankah [General machine-building standards for cutting modes for the technical standardization of work on metal cutting machines]. Part 1. M.: Machine building, 1974. 406 p. (Rus)

17.Spravochnik tehnologa-mashinostroitelya [Handbook for a technologist in machine building]. Vol. 2. Ed. by Dalskiy A.M., Kosilova A.G., Mescheryakov R.K., Suslov. A.G. M.: Machine building-1, 2001, 912 p. (Rus)

18.Grechishnikov A.G. et al. Rezhuschie instrumentyi [Cutting tools]. Stary Oskol: TNT, 2009. 388 p. (Rus) 